\title{
Possibilidades, limites e desafios da humanização no Sistema Único de Saúde (SUS)
}

\author{
Possibilities, limitations and challenges on humanization in the National Brazilian Health System \\ Posibilidades, limitaciones y desafíos de la humanización en lo Sistema Único de Salud
}

\begin{abstract}
A humanização tem conquistado espaço no debate acadêmico da Saúde Coletiva nos últimos anos e, também, tem recebido destaque dos usuários, trabalhadores e gestores como um dos caminhos para as necessárias transformações do Sistema Único de Saúde (SUS). Nesta pesquisa, de caráter qualitativo e inspiração cartográfica, fazemos um exercício de reflexão sobre a nossa atuação profissional visando efetivar a Política Nacional de Humanização da Atenção e da Gestão - HumanizaSUS (PNH) no Hospital Universitário de Dourados, no Mato Grosso do Sul. Fizemos um breve histórico político-institucional da humanização até a sua constituição como uma política do SUS. Apresentamos os princípios, as diretrizes e os dispositivos da $\mathrm{PNH}$. Depois, promovemos um diálogo entre a nossa experiência de trabalho no hospital e as estratégias que compõem a referida Política. Ao longo do texto, citamos algumas situações, nomeadas por nós como recortes do cotidiano, com o intuito de demonstrar as possibilidades, os limites e desafios que vivenciamos na instituição. Em nossa discussão, utilizamos as contribuições da Reforma Sanitária, da Reforma Psiquiátrica e da Saúde Coletiva, pois tratam de inovações que são reafirmadas nas propostas que constituem a PNH. Consideramos que a humanização contribui com o processo que está em curso na superação do modelo hegemônico, e que aposta em outros modos de produzir saúde que prescindam da tutela, controle e da compaixão, na busca pela produção de autonomia e corresponsabilidade entre os atores.
\end{abstract}

Catia Paranhos Martins Dissertação (Mestrado), 2010. Programa de Pós-Graduação em Psicologia, Universidade Estadual Paulista, campus de Assis catiaparanhos@hotmail.com
Palavras-chave: SUS. Humanização. Saúde Coletiva. Keywords: SUS (National Brazilian Healthy System). Humanization. Collective Health.

Palabras clave: Sistema Único de Salud. Humanización. Salud Colectiva.

Texto completo disponível em:

http://polo3.assis.unesp.br/posgraduacao/teses/psicologia/

CATIA\% 20P.pdf 